\title{
COLLAPSE AND REHABILITATION OF STEEL TANKS ROOF STRUCTURES
}

\author{
F. Turcic ${ }^{1, *}$, I. Luketina, M. Plisic \\ ${ }^{1}$ Civil Engineering Institute of Croatia, Zagreb, Croatia \\ Department of Steel structures \\ *(Corresponding author: E-mail: franjo.turcic@igh.hr)
}

Received: 10 November 2006; Revised: 3 May 2007; Accepted: 15 May 2007

\begin{abstract}
Steel roof structures of two identical cylindrical heating oil tanks, located in Zagreb, Croatia, suffered great deformations and partly collapsed in 1993 and 1994, after two decades of continuous use. The tanks are each 20,000 cubic meters in volume, $45.7 \mathrm{~m}$ in diameter, $12.5 \mathrm{~m}$ in sheathing height, and each of them has a central column in the middle. The cause of damages has been analyzed. An account is given to poor original design, with respect to relevant influences: all types of loads, adequate static system and boundary conditions for individual load types. Necessary additional calculations have been performed and described. The mechanism of the activation and development of the damages are explained. Solutions implemented in the rehabilitation works are also presented. The results and analyses are presented in detail, as they are deemed highly instructive and of interest to a variety of professionals. The tank type analyzed in this paper can be considered as an internationally typical structure as it has been widely used in many locations worldwide. The authors believe that some of similar failures occurred also in the other locations, but, according to available literature, the corresponding reports have proven to be scarce.
\end{abstract}

Keywords: Steel tanks, roof structures, collapse, damage, rehabilitation

\section{INTRODUCTION}

Steel roof structures of two identical heating oil tanks, each 20,000 cubic meters in capacity, located in Zagreb, Croatia, partly collapsed in 1993 and 1994, after two decades of continuous use.

According to design information, the load-bearing roof structure consisted of 16 fan trusses, which are supported on the one side by tank sheathing and by the central column on the other, purlins, rafters and metal sheet covering.

The followings are described in the paper: original structure, structural damage, cause of damage, and rehabilitation conducted in 1993 and 1994 on R5 and R6, and once again in 1996, only on R6. No difficulties have been reported since the last rehabilitation work.

Part of this article was published in Europe 2006. [1]

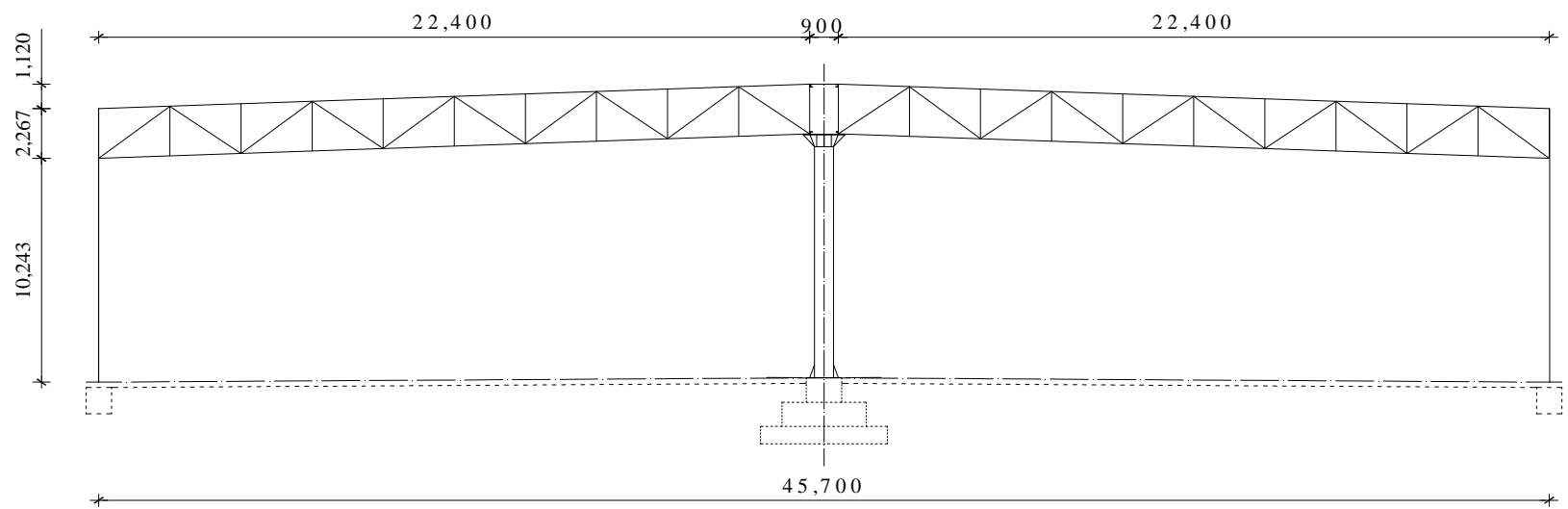

Figure 1. Tank Cross Section and Dimensions (mm) 


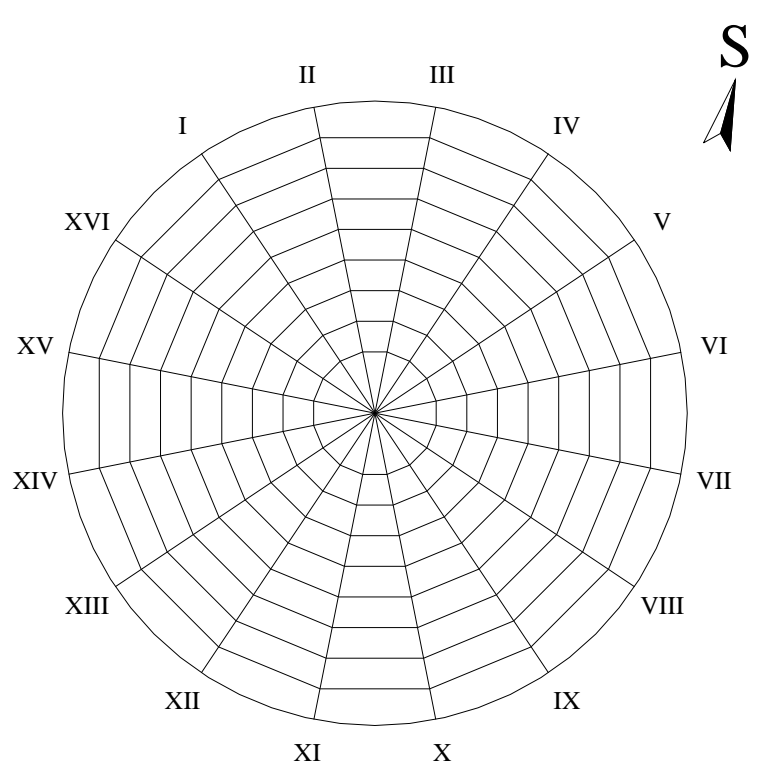

Figure 2. Plan View of Roof Trusses and Purlins

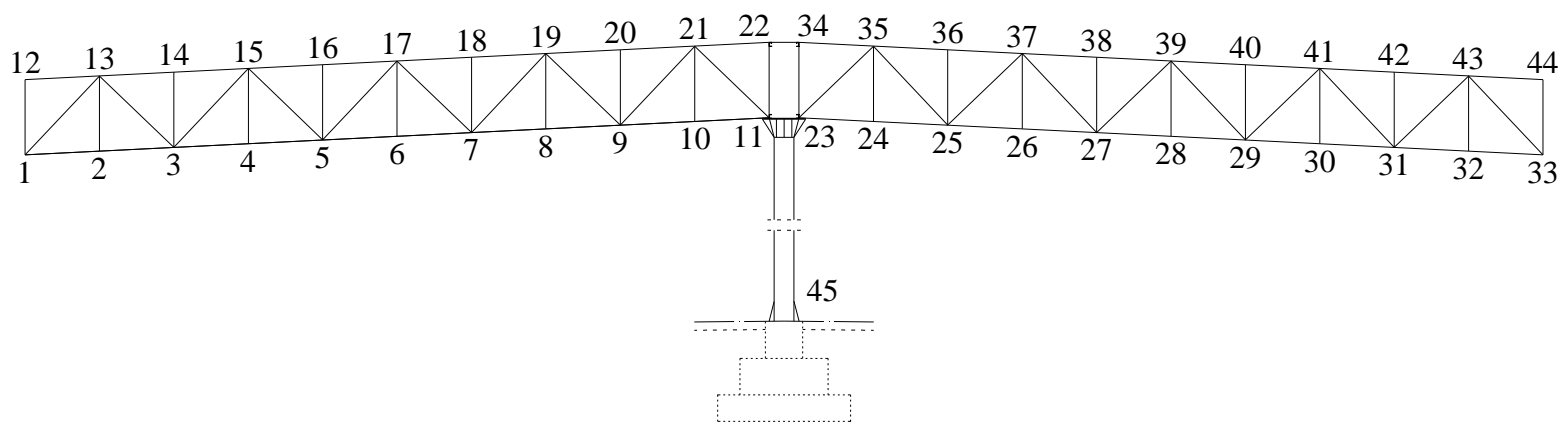

Figure 3. Roof Truss and Central Column Node Designations

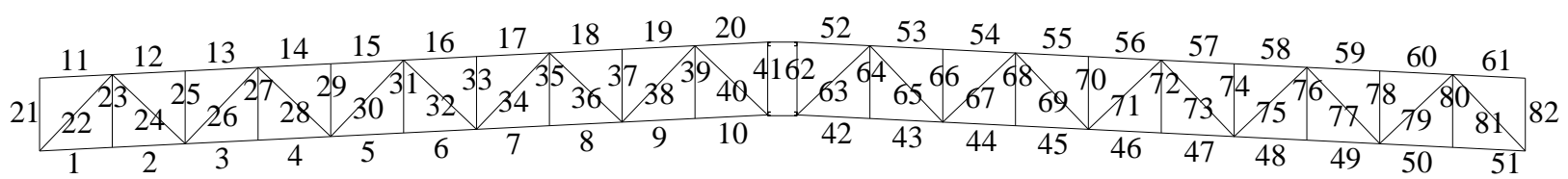

Figure 4. Roof Truss Member Designations

\section{PRESENTATION OF THE INITIALLY DESIGNED AND BUILT ROOF STRUCTURE}

The steel sheet cover of $5 \mathrm{~mm}$ in thickness was locally welded onto the top surface of roof trusses. Purlins are made of steel IPE profiles: 18, 18, 16, 14, 12, 10, 10 and 10 supported in nodes 13 through 20. Steel sheet thicknesses at the tank sheathing level are: 22, 15, 15, 13, 10, 8 and $7 \mathrm{~mm}$. At top, the sheathing is stiffened with the steel angle L100x100x10. Roof trusses are connected to the sheathing and the central column in the following nodes: 1, 12, 33, 34, 11, 22, 23 and 44 shown in Figure 3 above. These connections are rigid and no relative movement is allowed. 
The central column is a hollow cylindrical tube $600 \mathrm{~mm}$ in diameter and $8 \mathrm{~mm}$ in wall thickness. At node 45 , this column was not firmly linked with the steel sheet at the base or with the foundations, and hence a vertical upward movement was enabled.

At nodes 2 to 7, the lower chord of roof trusses was laterally attached to purlins by means of inclined struts. However, such lateral support was not provided for in nodes 8, 9 and 10 of the lower chord.

\section{DESCRIPTION OF DAMAGE TO TANK R5}

The damage to the roof of the tank R5 was registered in September 1993.

After the tank was emptied and washed, the following internal and external damage was observed:

(1) About 40 percent of the roof area caved in through shell penetration, including also the roof trusses XIII, XIV, XV, XVI and I. Thus a depression in form of an ellipse shaped basin $(1.75 \mathrm{~m}$ in maximum depth, with ellipse axes 35 and $15 \mathrm{~m}$ in length) was created on the roof surface.

(2) Last two envelopes of the sheathing, together with edge bracing and railing on about $1 / 3$ of the perimeter (about $45 \mathrm{~m}$ ) are heavily deformed and damaged.

(3) The following roof truss members failed either due to axial tensile forces or bending action along nodes (Table 1):

Table 1. Failure due to Axial Tensile Forces or Bending

\begin{tabular}{|l|l|l|}
\hline Truss No. & Element No. & Place of failure \\
\hline \multirow{5}{*}{ I } & 2 & next to node 2 \\
\cline { 2 - 3 } & 11 & next to node 12 \\
\cline { 2 - 3 } & 12 & next to node 14 \\
\cline { 2 - 3 } & 24 & in the middle \\
\hline XIII & 9 & next to node 9 \\
\hline XIV, XV & 2 & next to node 3 \\
\hline \multirow{2}{*}{ XVI } & 12 & next to node 13 and 14 \\
\cline { 2 - 3 } & 24 & in the middle \\
\hline
\end{tabular}

(4) The following roof truss members were buckled plastically within or outside the truss plane (Table 2):

Table 2. Plastically Buckled Roof Truss Members

\begin{tabular}{|l|l|l|}
\hline Truss No. & Element No. & Place of failure \\
\hline XIII & 14 & in the plane \\
\hline $\begin{array}{l}\text { I, II, IX, X, XI, } \\
\text { XIII, XIV, XV, } \\
\text { and XVI }\end{array}$ & $7,8,9$ and 10 & outside of the plane \\
\hline $\begin{array}{l}\text { I, XIII, XIV, } \\
\text { XV and XVI }\end{array}$ & 36,37 and 40 & outside of the plane \\
\hline
\end{tabular}


(5) The foot of the central column moved from the initial position by $105 \mathrm{~mm}$, approximately in the direction of the truss no. XI.

(6) In the zone of roof collapse, the first bearing member to collapse was the purlin INP 18 which is connected to truss no. I in node 13 . This was followed by failure of several elements of the rafters L65-65-6.

The above described damage can be seen in Figures 5, 6, 7 and 8.

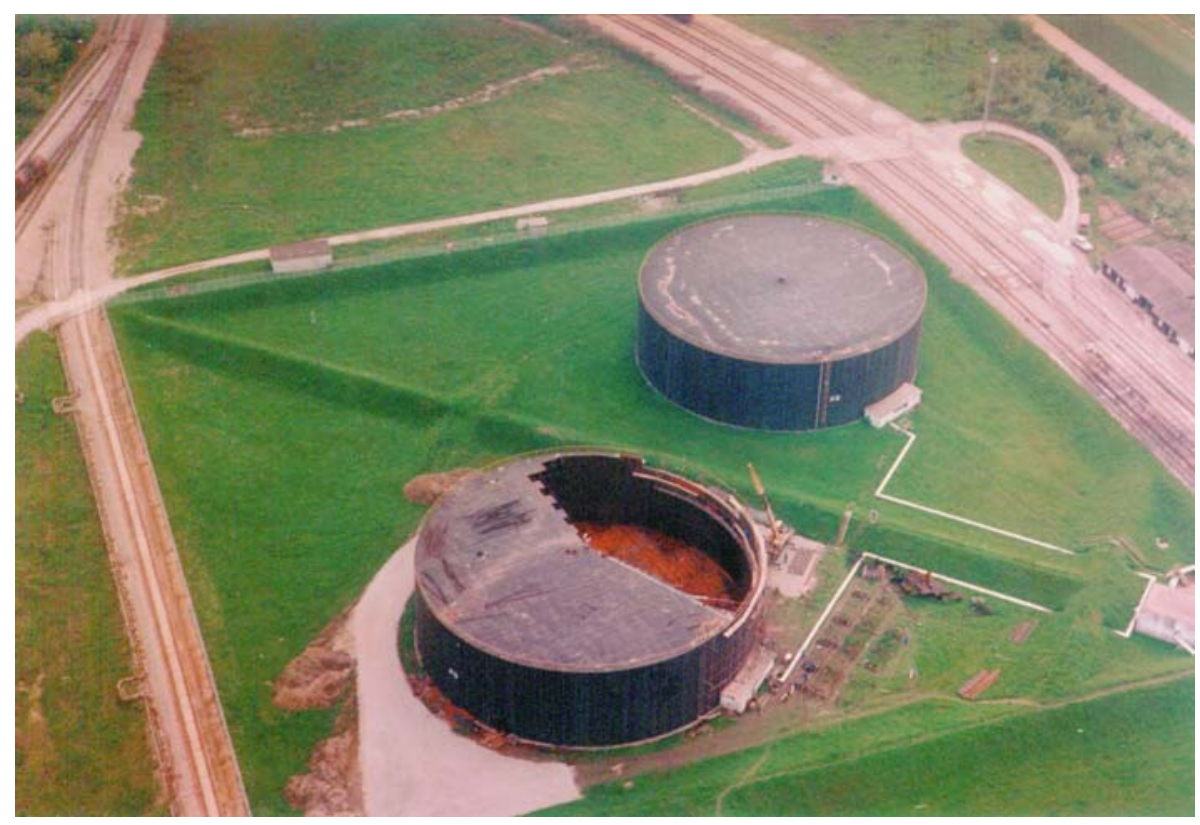

Figure 5. View of Tanks R5 and R6 (R5 during the Rehabilitation Stage)

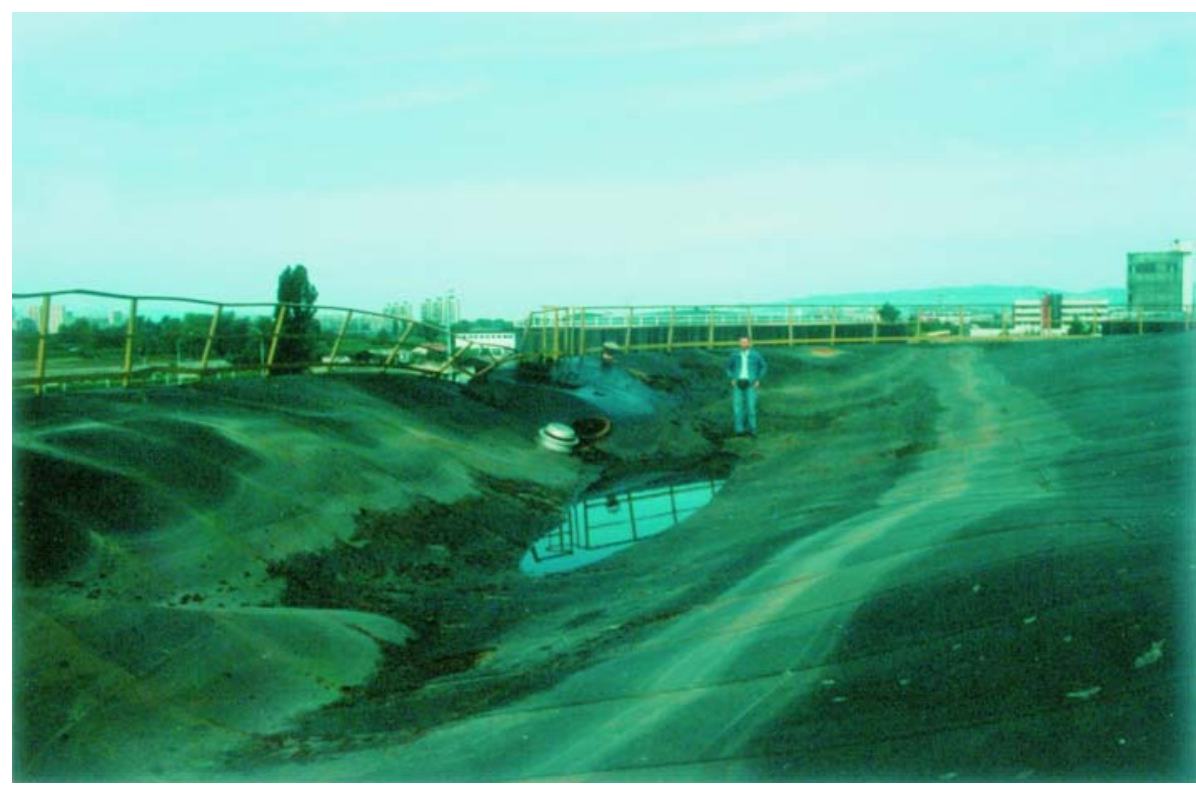

Figure 6. Form of Depression on the Roof Surface 


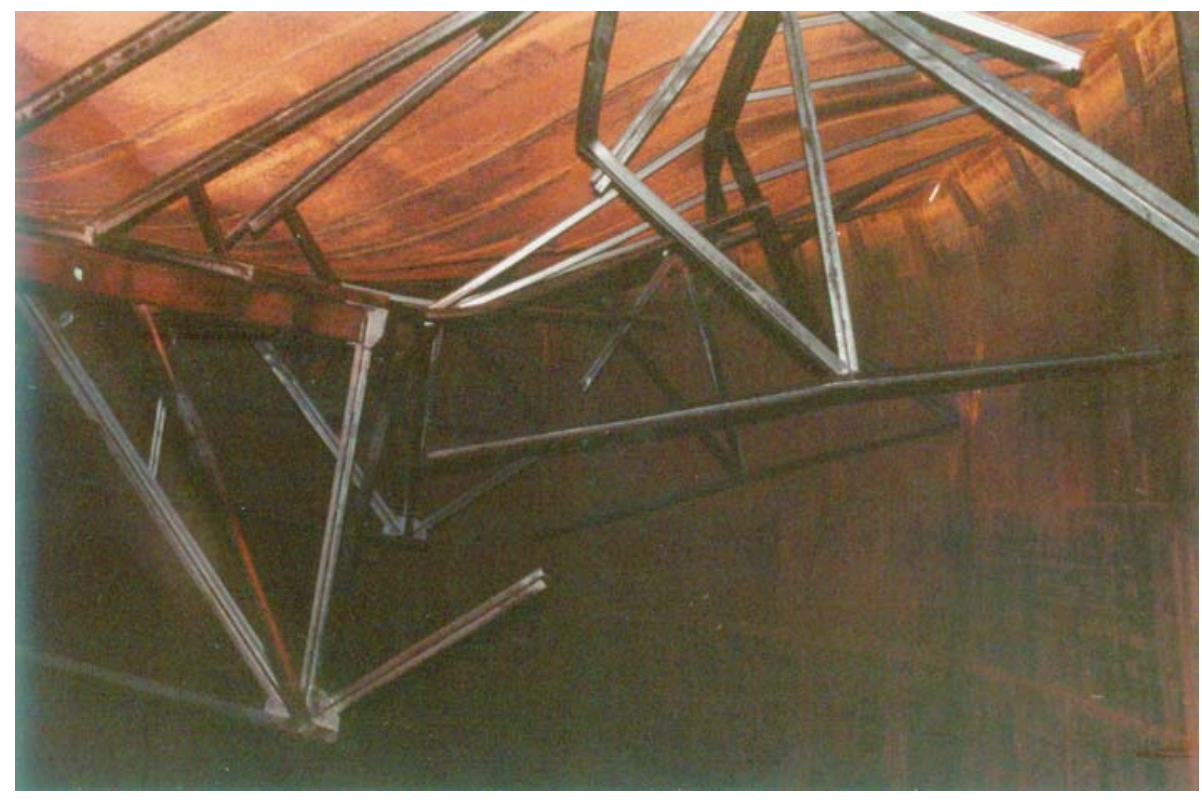

Figure 7. Broken Roof Trusses

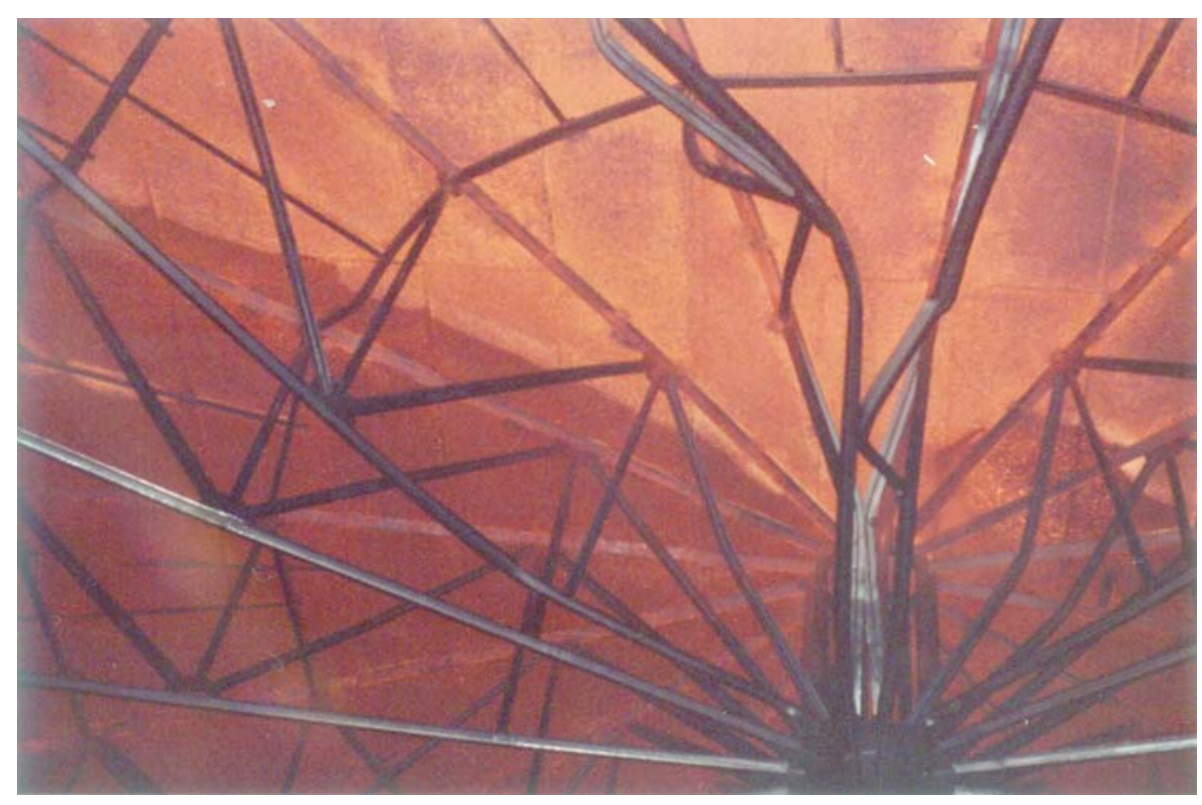

Figure 8. Deformed Roof Trusses in the Vicinity of the Central Column

\section{COLLAPSE CAUSE ANALISYS OF THE TANK R5}

The initial design was inspected in the first step of the analysis. It was established that the roof truss was dimensioned as the simple-supported beam in the length from the envelope to the central column ( $\mathrm{L}=22,400 \mathrm{~mm}$ ) for the following loads: self weight, uniform snow $0.75 \mathrm{kN} / \mathrm{m}^{2}$, and uniform wind: $-1.3 \times 0.60=-0.78 \mathrm{kN} / \mathrm{m}^{2}$.

The roof members were designed quite correctly for the assumed static system and for the assumed load. 
The following deficiencies in analysis, and differences between the design assumptions and actual realization of the structures, were noted.

(1) The central column in node 45 is not fixed to the base or to the foundations. Therefore a vertical upward displacement is activated. The continuity of roof trusses is ensured via rigid connections to the central column and via the roof sheeting. Thus, the real static system differs from the system assumed in the original design.

(2) The influence of the sudden change in temperature at the cover and at a portion of the envelope (above the level of the partly filled tank) during summer rain, particularly when combined with the wind, was not taken into account.

(3) The value of $0.75 \mathrm{kN} / \mathrm{m}^{2}$ assumed as superimposed load in the design is too small. According to API standard [2], such load should amount to at least $1.22 \mathrm{kN} / \mathrm{m}^{2}$. In Zagreb, the value of 1.25 $\mathrm{kN} / \mathrm{m}^{2}$ of snow load is normally used for light steel structures.

(4) The possibility of negative pressure was not taken into account as vents installed on the roof of the tank R5 become activated only when the negative pressure (vacuum) during service exceeds 0.22 bars. Here it should however be noted that, unlike tank R5, tank R6 had a free opening so that vacuum could not be created in the tank.

During the analysis of causes of the collapse on R5 the main cause could not be determined with a high level of certainty, because of the extent of damage. This became possible only in 1994 when permanent deformations were recorded on the roof of the neighbouring tank R6.

\section{DESCRIPTION OF DAMAGE TO TANK R6}

In August 1994, during rehabilitation and strengthening of the tank R5, the identical tank R6 was visually inspected and local deformations (depressions) were found in the roof area around nodes 13 and 14 , almost along the entire perimeter.

After the tank was emptied and washed, the following damage was recorded.

(1) The footing of the central column (node 45) deviated from design position by $11 \mathrm{~cm}$.

(2) The following roof truss members were damaged (Table 3):

Table 3. Damaged Roof Truss Members

\begin{tabular}{|l|l|l|}
\hline Truss No. & Element No. & Type of damage \\
\hline I to XVI & 24 & plastic buckling \\
\hline I to XVI & 2 and 12 & plastic deformations \\
\hline IV, V and VI & 11 & plastic buckling \\
\hline VIII & 23 & plastic buckling \\
\hline
\end{tabular}

(3) The deflections on the roof surface are such that rainwater remains on the roof despite the roof slope. Typical appearance of roof girder deformations on R6 is shown in Figures 9, 10 and 11. Figure 9 shows the appearance of damaged roof truss members, Figure 10 indicates the deflection with water pools on the roof and Figure 11 depicts the displacement of the central column footing. 


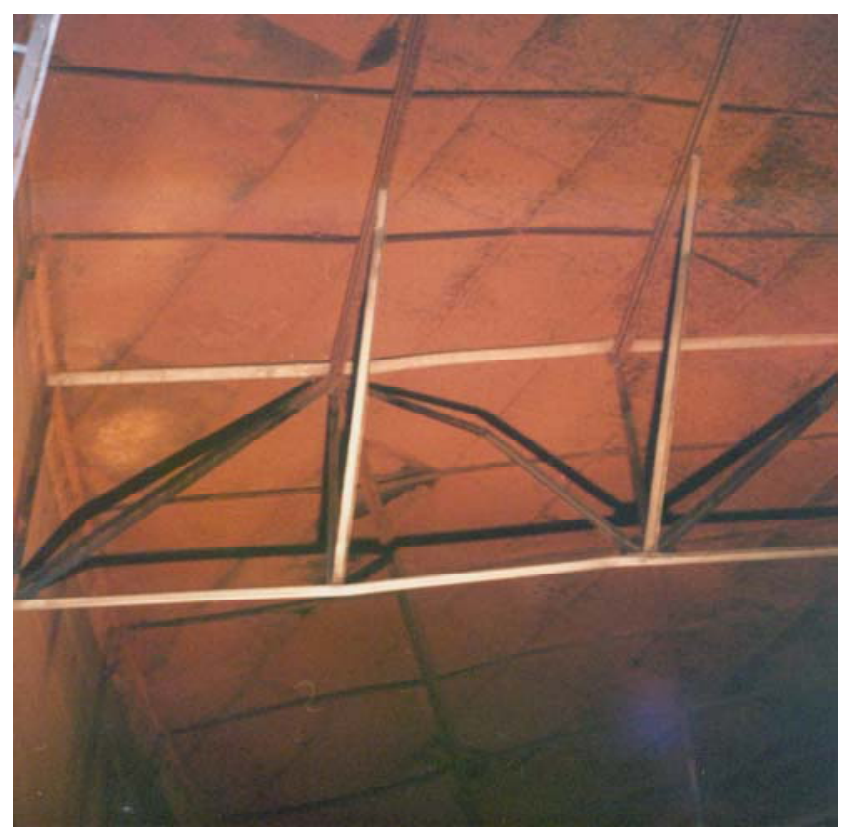

Figure 9. Damaged Roof Truss Members

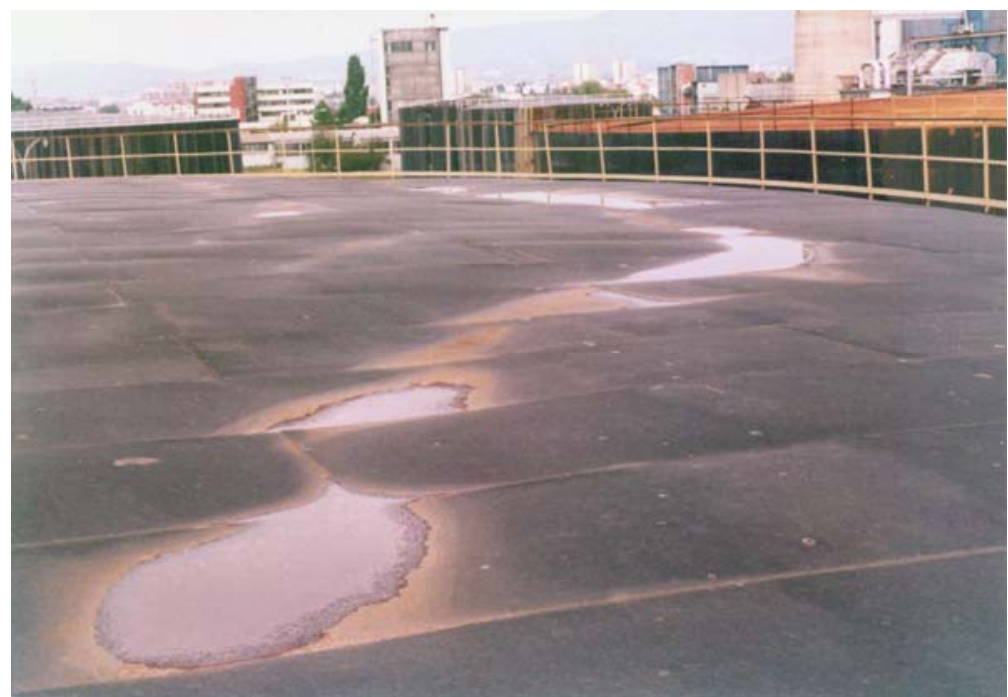

Figure 10. Depressions on the Roof Surface

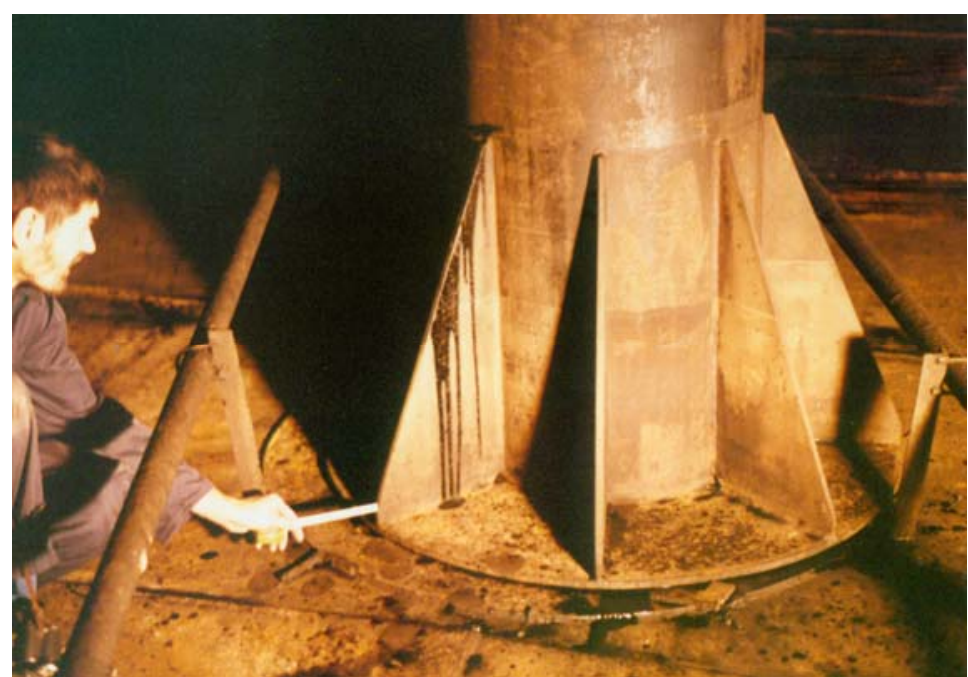

Figure 11. Central Column Footing Displacement 


\section{DAMAGING CAUSES OF TANKS R5 AND R6}

Once the type of damage to R6 was defined, it was possible to determine, with a relatively high level of certainty, basic causes of initial damage to R5 and R6, and to prove them by calculations. It became clear that the critical event was the insufficient compressive capacity of the member 24 .

If appropriate load combinations are analyzed using adequate static systems, then this can also be confirmed in numerical form.

Axial force results for studied roof truss members are presented in Table 4 under the following conditions.

(1) The self-weight of the cover and roof structure on the truss of $22.4 \mathrm{~m}$ in span, fixed at the points of connection with the central column, and with restrained displacement in the direction of the bottom chord in nodes 1 and 33 (column 2) is assumed.

(2) Uniform wind, $-1.3 \times 0.6 \mathrm{kN} / \mathrm{m}^{2}$ in intensity, plus buoyant force in the direction of the hollow central column in case of full tank, minus self-weight of the roof structure and central column, on the roof truss $45.7 \mathrm{~m}$ in span, with an unrestrained vertical displacement above the central column is assumed. Unrestrained displacement of nodes 1 and 33 was noted in the direction of the bottom chord. Restrained displacement in nodes 12 and 44 in the direction of the top chord (column 3).

(3) In case of summer rainfall, the temperature at the metal sheet cover and at a part of the tank sheathing falls by temperature change as $30^{\circ} \mathrm{C}$, at the roof truss $45.7 \mathrm{~m}$ in span.

The calculated free vertical displacement (uplift) at the central column amounts to $17 \mathrm{~mm}$ for the load combination case (2).

It can be seen from the preceding description that boundary conditions at the sheathing support were defined for individual design models (i.e. load or combination) based on the direction of node deformation. The displacement is restrained if the deformation of nodes $1,12,33$ and 44 in the direction of the top or bottom chord is outside of the tank perimeter, while the displacement is unrestrained if the deformation occurs within the tank perimeter.

Table 4. Axial Forces in the Truss Members $(\mathrm{kN})$

\begin{tabular}{|c|c|c|c|c|c|c|c|c|}
\hline \multirow{3}{*}{$\begin{array}{l}\text { Element } \\
\text { No. }\end{array}$} & \multicolumn{4}{|c|}{ Single or combined loads } & \multicolumn{2}{|c|}{ Combinations } & \multirow{2}{*}{\multicolumn{2}{|c|}{$\begin{array}{c}\text { Compressive bearing } \\
\text { capacity }\end{array}$}} \\
\hline & \multirow{2}{*}{$\begin{array}{l}\text { Self } \\
\text { weight }\end{array}$} & \multirow{2}{*}{$\begin{array}{l}\text { Self weight } \\
+ \text { wind } \\
+ \text { buoyancy }\end{array}$} & \multicolumn{2}{|c|}{$\Delta \mathrm{T} 30^{\circ} \mathrm{C}$} & \multirow{2}{*}{$\begin{array}{l}\Sigma \\
2+4+5\end{array}$} & \multirow{2}{*}{$\begin{array}{l}\Sigma \\
3+4\end{array}$} & & \\
\hline & & & roof & sheathing & & & Allowable & Critical \\
\hline 1 & 2 & 3 & 4 & 5 & 6 & 7 & 8 & 9 \\
\hline 1 and 2 & -4 & -10 & 52 & -108 & -60 & 42 & -58 & -88 \\
\hline 9 and 10 & -44 & -20 & -49 & -13 & -106 & -69 & -58 & -88 \\
\hline 11 & 0 & 44 & -133 & 31 & -102 & -89 & -128 & $\begin{array}{l}-192 \\
\end{array}$ \\
\hline 20 & 32 & 62 & -7 & -88 & -63 & 55 & -128 & -192 \\
\hline 24 & 31 & -10 & -17 & 16 & 30 & -27 & -20 & -30 \\
\hline
\end{tabular}

The following conclusions can be derived from the calculations results:

According to local conditions in Zagreb area, the load combination $3+4+5$ is quite realistic, i.e. the load combinations as : self-weight of the cover, roof trusses and central column, + strong summer 
wind, + sudden fall in temperature at the metal sheet cover and tank sheathing (assumed in our calculations to be $\Delta \mathrm{T}=30^{\circ} \mathrm{C}$ ) due to a summer shower, positive buoyant force on central column. It should however be noted, comparing results from the columns 6 and 9, that the compressive strength of members in the bottom chord of roof trusses 9 and 10 would be exceeded in the case of the load combination $2+4+5$.

Members 9 and/or 10 will buckle elastically or plastically first, but the load bearing system continued to function, until buckling of the diagonal 24 of the roof truss occurred.

The difference in pressure (values in excess of the bottom chord capacity) due to fall in sheathing temperature was fully assumed by top chord elements of the roof truss, and thus we come to the relevant load combination $3+4$, as given in column 7 (the maximum prescribed design wind value was included).

In this combination, the member 24 will buckle (after elastic buckling of members 9 or 10), even if the maximum prescribed design wind intensity is not attained. This is because the forces in column 7 are less than the forces in member 24 .

(4) Presence of the additional pressure is exerted by sheathing onto the top chord after buckling of members 9 and 10. The force generated in the diagonal caused by temperature change could be released only after failure of the top chord members,

(5) The wind load at the roof level may not be uniform, i.e. the wind resultant was assumed to move from the centre to the side which attracts a larger wind pressure.

This field of the truss, after buckling of the member 24, acts as a frame, resulting in deformation of chord members 2 and 12 due to bending along nodes. At this time, initial downward deflections begin to form in the area around nodes 13 and 14. Rainwater gradually accumulates in these deformed zones.

It is at this stage of roof deformations that such occurrences were recorded in tank R6.

The occurrence of first deformations, and their gradual increase ultimately to failure, was a time dependent process that might spread over several years, during which the area was probably affected by several events characterized by repeated superposition of a variety of negative load combinations.

No one noted nor understood unfavourable or warning signs that formed on the load bearing structure of tank R5 in the initial stage.

In this respect, it can be seen from documents about maintenance of the tank $\mathrm{R} 5$ that great deflections from linearity were registered and repaired 1986. At the level of members 9 and 10 of the roof truss bottom chord, no abnormality was noted, analyzed, commented or explained.

As to tank R5, it can be concluded that chord members 2 and 12 were no longer able to withstand negative load combinations from self-weight, snow and possibly suction wind present in the newly formed frame-shaped static system after buckling of the diagonal member 24, which resulted in the deformation and bending ruptures of the members. After this, the roof failed in the vicinity of nodes 13 and 14 on a part of the perimeter. The rainwater started to accumulate in the valley formed by this failure and the volume of the valley gradually increased because of the water weight, and hence the diagonal member 24 was converted into a tensile member. Once the volume of the valley and the 
quantity of the accumulated rainwater reached the critical level, this new tensile member 24 failed and the part of the roof around the valley caved in.

It is only at this stage that this phenomenon was noted at the tank R5 in 1993. The failure stages are shown in Figure 12.
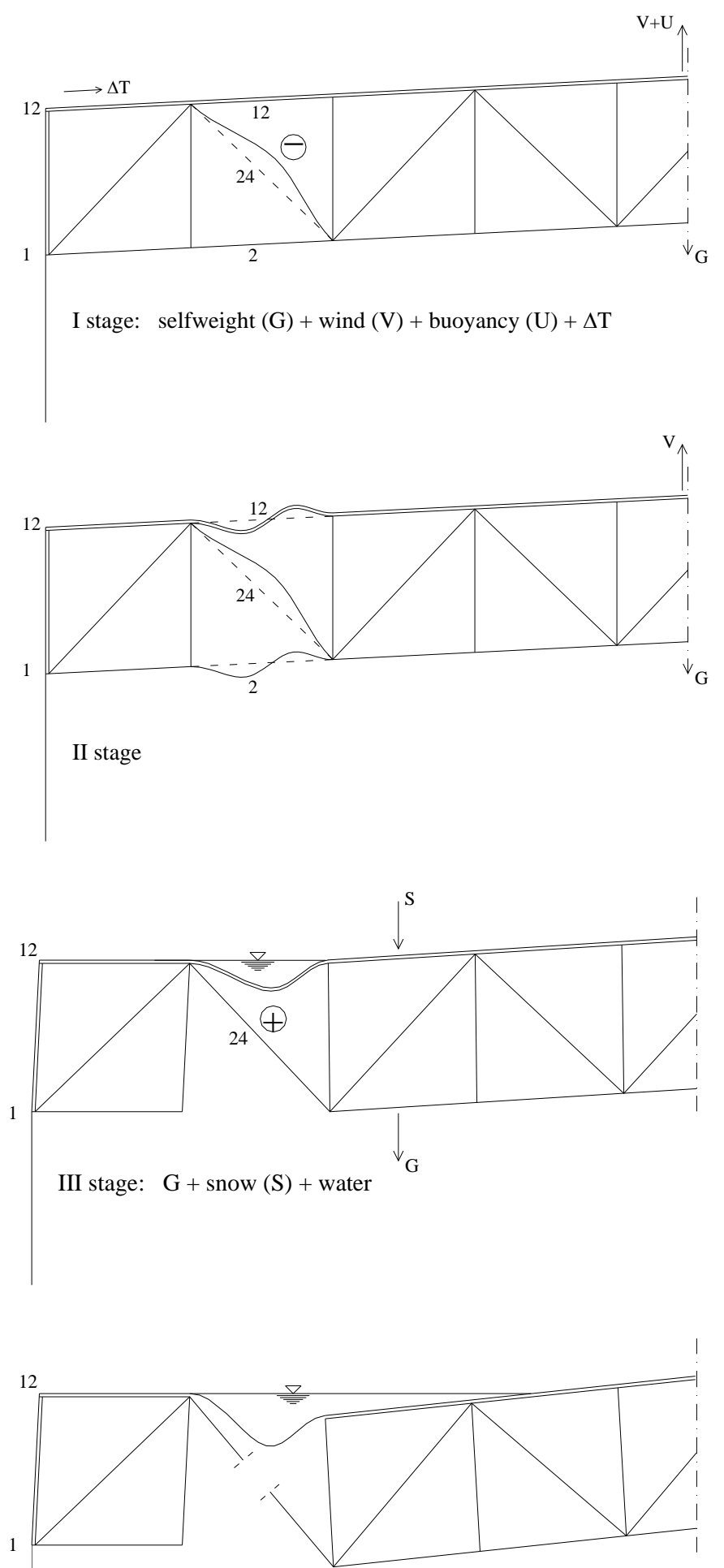

IV final stage: collapse after breakdown of D24

Figure 12. Stages of Damage Development 
It can be seen from the photograph of the roof metal sheet area in the valley that the process lasted for some time. The mud and corrosion isohypse traces show several valley filling levels, and point to longer periods of rainwater deposition and evaporation.

The question should now be put as to why and when the central column footing in node 45 were displaced at tank R6 (i.e. in initial phase of damage development and again in 1996.), and at tank R5 (registered after final collapse).

As already stated in the introductory section of the paper, no connection was required or planned between the central column footing and the base or foundations. Some sort of makeshift connection was nevertheless realized in form of "chairs" i.e. L-shaped upright metal sheets weakly welded onto the tank base (Figure 13). Their form was such that they enabled free vertical movement, but prevented lateral movements. This connection can be seen in photographs. The number and dimensions of such chairs/supports were not registered or figured in the design documents. It seems that these chairs were used as a temporary means of support during assembly work.

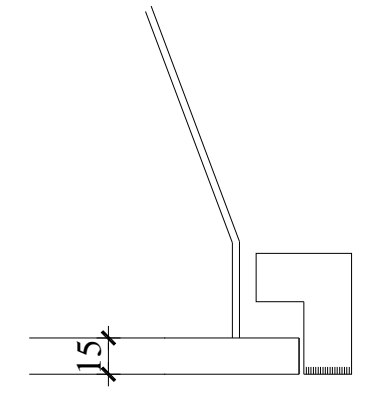

Figure 13. Lateral Support of the Central Column Footing

It can be seen in photographs the situation during inspection that the column footing failed such restraints during the lateral displacement.

Roof trusses are characterized by structural continuity in the zone above the central column. In case of sudden loss of stability of compressed members 9 and/or 10 of the bottom chord in a group of roof trusses (which are due to unsymmetrical wind load subjected to maximum load, or are geometrically weaker than others), the connection at the top of the central column rotates and moves the central column footing in the lateral direction. This movement is instantaneous and strong, resulting in the breakdown of weak restrainers.

The followings were determined during analysis of the sudden fall in temperature at the level of the metal sheet cover and sheathing:

(6) Rapid cooling of the metal sheet cover generates pressure in the entire top chord, in members 7 , 8,9 and 10 of the bottom chord, and in the diagonal 24.

(7) Rapid cooling of the sheathing results in compression in the bottom truss chord and in tension in the diagonal 24, but due to rapid overstepping of compressive strength of lower chord members 9 and 10 the difference is registered, as the compression affecting top chord members which in turn increases compression in members 24.

Obviously, the rapid cooling of the cover and sheathing cannot by itself endanger the safety, bearing capacity and stability of roof trusses, regardless of the temperature change, as the load due to temperature change is released already during elastic bending of members. This behaviour, however, does not hold true for the diagonal member 24 in combination with other loads, because the influence 
of temperature change can be released only after the compressive strength of members in the top chord of the truss is exceeded.

\section{STRENGTHENING AND REPAIR MEASURES TAKEN IN 1993 AND 1994}

The following major works were undertaken in the scope of tank rehabilitation activities on tanks R5 and R6:

(1) All roof truss parts or elements at sheet metal and sheathing levels, that either collapsed or were affected by plastic deformation, were replaced. Central column was corrected in designed position.

(2) All roof truss members were strengthened so as to be able to withstand the service load of 1.25 $\mathrm{kN} / \mathrm{m}^{2}$, which were defined as necessary through calculations.

(3) The hollow steel-made central column was filled with concrete.

(4) Four latticed bracings were added on the tank R6 in order to further stabilize the top chord of roof trusses at the roof level.

(5) The central column footing was fillet-welded along the circular perimeter to the sheet metal at the tank bottom level.

(6) Node 9 at the bottom chord was laterally linked to purlins by diagonal bracing.

\section{NEW PROBLEMS WITH TANK R6 IN 1996 - ADDITIONAL REPAIRS ONLY ON R6}

In 1996, it was observed that the heating oil leaked from the tank R6. A crack of $1300 \mathrm{~mm}$ in length was discovered at a weld situated at the tank base, about $80 \mathrm{~mm}$ away from the central column footing. The cause of the cracking was related to the functional use of the roof bearing structure.

In addition to this cracking at the base level, some new deformations were recorded at the roof structure:

(1) Large local and plastic deformations of the member 10 at the bottom chord on roof trusses X, XI, XII, and XIII (i.e. buckling in the truss plane).

(2) Elastic and plastic deformations on the bottom chord on roof trusses IV, VIII and IX.

The causes of the above deformations and phenomena are similar to those explained above.

After the investigation in 1996, the tank R6 was subjected to the following additional repairs:

(1) The fillet weld, by which the central column footing was linked to the base, was removed.

(2) Roof truss supported on the central column, in nodes 11 and 23, were converted from fixed supports to movable supports. 
(3) The top part of the central column head at R6 was radially anchored with 8 inclined anchors to the tank sheathing above the base (This intervention was probably unnecessary but considered as an additional safety measure, because weight of the concrete in central column was sufficient to prevent vertical movement).

(4) The lateral displacement of the central column footing was prevented via lateral restraints situated at the tank base.

(5) Members 9 and 10 were adjusted to improve their linearity.

\section{REHABILITATION WORKS WITH TANK R5}

Making reference to the case for R6, it was recommended to the Client (Report IGH No 25-602/1996, from 22 Nov. 1996.) to undertake the same rehabilitation works on tank R5 as it was carried out for R6 described under section 8 of this paper to prevent similar collapse.

The completed works reported from the Client indicates the followings.

a) Recommended rehabilitation on tank R5 has not been completed. Only the vents on the roof (see section 4 (4)) have been removed and replaced with free openings.

b) Both tanks since then have been in continuous use. No major discrepancies have been reported.

Authors of this paper have not seen the tank R5 since 1994. Our presumptions are as follows.

a) Member 10 plastically buckled, because the theoretical critical compressive capacity will be exceeded already due to self weight of the structure plus $50 \%$ of the prescribed snow load, or for load described under b).

b) Also, buckled bottom chords of some trusses along the whole length (elastically or plastically), because the theoretical critical compressive capacity will be exceeded due to fall in sheathing temperature (see table 4 and explanation in section 6 (3)).

c) We assume the central column footing is not displaced, because it is welded to the tank bottom. It seams quite obvious that the inclinations of the column, caused by buckling of the trusses elements, did not result in the cracking of tank bottom sheathing metal welds. If it happens, the heating oil leaks would have been observed.

\section{CONCLUSIONS}

The causes of damage to roof structures of two identical heating oil tanks are analyzed. The failure causes are accounted to poor original design under Section 4, with respect to relevant factors as types of loads, adequate static system and boundary conditions for individual load types.

The causes of the damages on tanks R5 and R6, and also the mechanism of the beginnings and development of the damages are described in detail under Section 6, which corresponds to the professional reports submitted to the Client (in Croatian). 
Strengthening and repair measures, taken in 1993, 1994 and 1996, are described under Section 7 and 8.

The results and analyses made during this appraisal are presented in detail, as they are deemed highly instructive and of interest to the engineering, building and construction professionals.

In this respect, it should be noted that the tank type analyzed in this paper can be considered as an internationally typical structure, as it has been widely used in many locations worldwide. The authors believe that similar failure occurred in the other locations, although failure reports in literature were scarce.

\section{REFRENCES}

[1] Turcic, F., Luketina, I. and Plisic, M., "The Cause of Collapse and Rehabilitation of Steel Tanks Roof Structures”, In: Gizejowski, Kozlowski, Sleczka \& Ziolko (eds), Progress in Steel, Composite and Aluminium Structures, 2006, pp. 729-736. Taylor \& Francis 2006. Used with permission.

[2] API STANDARD 650: 1980, "Welded Steel Tanks for Oil Storage” 